\title{
Effects of cisplatin on mitochondrial function and autophagy-related proteins in skeletal muscle of rats
}

\author{
Dae Yun Seo ${ }^{1, \#}$, Jun Hyun Bae $e^{2,5, \#}$, Didi Zhang ${ }^{3}$, Wook Song ${ }^{2,4}$, Hyo-Bum Kwak ${ }^{5}$, Jun-Won Heo ${ }^{5}$, Su-Jeen Jung ${ }^{6}$, \\ Hyeong Rok Yun ${ }^{1}$, Tae Nyun Kim ${ }^{1}$, Sang Ho Lee ${ }^{7}$, Amy Hyein Kim ${ }^{1}$, Dae Hoon Jeong ${ }^{8}$, Hyoung Kyu Kim ${ }^{1}$ E Jin Han $^{1, *}$ \\ ${ }^{1}$ National Research Laboratory for Mitochondrial Signaling, Department of Physiology, College of Medicine, Smart Marine Therapeutics \\ Center, Cardiovascular and Metabolic Disease Center, Inje University, Busan 47392, ${ }^{2}$ Health \& Exercise Science Laboratory, Institute of \\ Sports Science, Seoul National University, Seoul 08826, Korea, ${ }^{3}$ School of Physical Education, Xiang Minzu University, Xianyang 712082 , \\ China, ${ }^{4}$ Institute of Aging, Seoul National University, Seoul 08826, ${ }^{5}$ Department of Biomedical Science and Engineering, Inha University, \\ Incheon 22212, ${ }^{6}$ Department of Leisure Sports, Seoil University, Seoul 02192, ${ }^{7}$ Department of Taekwondo, Dong-A University, Busan \\ $49315,{ }^{8}$ Department of Obstetrics and Gynecology, Busan Paik Hospital, College of Medicine, Inje University, Busan 47392, Korea
}

\begin{abstract}
Cisplatin is widely known as an anti-cancer drug. However, the effects of cisplatin on mitochondrial function and autophagyrelated proteins levels in the skeletal muscle are unclear. The purpose of this study was to investigate the effect of different doses of cisplatin on mitochondrial function and autophagy-related protein levels in the skeletal muscle of rats. Eight-weekold male Wistar rats $(n=24)$ were assigned to one of three groups; the first group was administered a saline placebo (CON, $\mathrm{n}=10)$, and the second and third groups were given 0.1 $\mathrm{mg} / \mathrm{kg}$ body weight (BW) $(\mathrm{n}=6)$, and $0.5 \mathrm{mg} / \mathrm{kg} B W(\mathrm{n}=8)$ of cisplatin, respectively. The group that had been administered $0.5 \mathrm{mg}$ cisplatin exhibited a reduced BW, skeletal muscle tissue weight, and mitochondrial function and upregulated levels of autophagy-related proteins, including LC3II, Beclin 1, and BNIP3. Moreover, this group had a high LC3 II/I ratio in the skeletal muscle; i.e., the administration of a high dose of cisplatin decreased the muscle mass and mitochondrial function and increased the levels of autophagy-related proteins. These results, thus, suggest that reducing mitochondrial dysfunction and autophagy pathways may be important for preventing skeletal muscle atrophy following cisplatin administration. [BMB Reports 2021; 54(11): 575-580]
\end{abstract}

*Corresponding author. Tel: +82-51-890-6727; Fax: +82-51-894-5714; E-mail: phyhanj@inje.ac.kr

${ }^{\#}$ These authors contributed equally to this work.

https://doi.org/10.5483/BMBRep.2021.54.11.132

Received 5 July 2021, Revised 2 September 2021, Accepted 6 October 2021

Keywords: Autophagy, Cancer, Cisplatin, Mitochondrial function, Skeletal muscle

\section{INTRODUCTION}

Cisplatin - cis-diamine-dichloroplatinum II-is an effective anticancer drug (1-3). The basic mode of treatment is cisplatin-induced DNA modification, activating damage recognition and repair of cancer DNA, cell-cycle arrest, and cell apoptosis $(4,5)$. Although cisplatin treatment is highly effective, many patients suffer from severe side effects, especially muscle atrophy $(6,7)$.

An animal model of cancer cachexia revealed that intraperitoneal injection of $1-3 \mathrm{mg} / \mathrm{kg}$ body weight (BW) (hereafter, $\mathrm{mg} / \mathrm{kg} \mathrm{BW}$ ) of cisplatin for several days caused weight loss and muscle atrophy $(6,8-12)$. Clinical trials have also indicated that skeletal muscle mass significantly decreased during chemotherapy in patients with advanced gastric cancer (13). Many previous studies have clarified that cisplatin-induced skeletal muscle atrophy or dysfunction is mainly caused by alterations in autophagy (14) and mitochondrial dysfunction $(6,14-17)$. It is widely accepted that the specific mechanism that helps maintain the muscle mass is supported by the IGF-1/PI3K/AKT/mTOR pathway (18). However, there is still a lack of studies that elucidate the effect of different concentrations of cisplatin administered on mitochondrial function, autophagy, and muscle mass in the skeletal muscles of animals.

Considering the significant mitochondrial dysfunction caused by cisplatin administration, it is clear that retaining mitochondrial function and quality control are critical for maintaining the muscle mass (19). A previous study showed that cisplatin toxicity affected oxidative phosphorylation, as measured by the respiratory control ratio (RCR), and decreased the respiratory capacity of cisplatin-administered cells (17). Mitochondrial dysfunction in skeletal muscle fibers of cisplatin-treated animals affected mitochondrial fusion and fission proteins, such as dynaminrelated protein 1 (Drp 1), and caused muscle atrophy (20). The results of this study indicated that cisplatin administration decreased mitochondrial biogenesis and skeletal muscle mass. Many other in-vitro studies have shown the effects of cisplatin treatment on levels of proteins related to mitochondrial bioge-

ISSN: 1976-670X (electronic edition)

Copyright (c) 2021 by the The Korean Society for Biochemistry and Molecular Biology

() This is an open-access article distributed under the terms of the Creative Commons Attribution Non-Commercial License (http://creativecommons.org/licenses/by-nc/4.0) which permits unrestricted non-commercial use, distribution, and reproduction in any medium, provided the original work is properly cited. 
nesis and indicated that mitochondrial dysfunction in cisplatin administration is associated with cisplatin toxicity (15) and muscle atrophy (21). Therefore, it is necessary to directly analyze mitochondrial function in skeletal muscles following cisplatin administration.

In addition to mitochondrial function, autophagy is a major metabolic regulator that protects against the side effects of chemotherapy involving cisplatin-administration (22). Autophagy in skeletal muscles is associated with muscle fiber regeneration (23) and modulates various molecular signaling pathways, as a chemosensitizer, in cisplatin-administered cancer cells (24). In a cisplatin-induced cachexia model, cisplatin-administration in fast-twitch skeletal muscle (e.g., gastrocnemius) increased cellautophagy markers (LC3 II, p62, and Beclin 1) by downregulating AKT and FOXO3a (8); LC3 II specially affects the autophagosome residual protein and mitochondrial function (25-27). However, most studies that analyzed autophagy in cancer cells were performed in vitro. Although cisplatin is associated with a severe side effect, i.e., muscle atrophy, very few studies have investigated the effects of varying doses of cisplatin on skeletal muscles.

The purpose of this study was to investigate the effects of different doses of cisplatin, including $0.1 \mathrm{mg} / \mathrm{kg} \mathrm{BW}$ of cisplatin, $0.5 \mathrm{mg} / \mathrm{kg}$ BW of cisplatin, and a control (CON; saline), on mitochondrial function and autophagy-related protein levels in

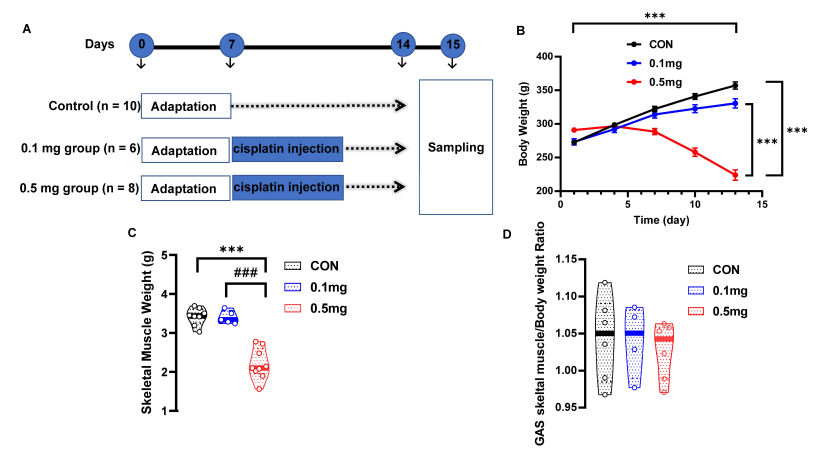

Fig. 1. Experimental procedure; body weight (BW, g), GAS skeletal muscle tissue weight (GAS, g), and GAS normalized by BW among CON $(n=10), 0.1 \mathrm{mg}(\mathrm{n}=6)$, and $0.5 \mathrm{mg}(\mathrm{n}=10)$ groups. (A) Experimental procedure. (B) Changes in BW over 15-days (time) for each group. (C) Differences in GAS of CON $(n=8)$ and $0.1 \mathrm{mg}(\mathrm{n}=5)$ groups as compared to the $0.5 \mathrm{mg}(\mathrm{n}=9)$ group. (D) Levels of normalization of GAS by BW in CON ( $\mathrm{n}=$ 6), $0.1 \mathrm{mg}(\mathrm{n}=4)$ and $0.5 \mathrm{mg}(\mathrm{n}=7)$ groups. Values were determined by densitometric quantification and are shown as the mean \pm standard error of the mean (SEM). Outliers in each group were excluded. CON, saline control; $0.1 \mathrm{mg}, 0.1 \mathrm{mg} / \mathrm{kg}$ BW of cisplatin administered in skeletal muscle; $0.5 \mathrm{mg}, 0.5$ $\mathrm{mg} / \mathrm{kg}$ BW of cisplatin administered in skeletal muscle. Statistical methods used were one and two-way repeated ANOVA with the factor time for BW and one-way ANOVA with Tukey's post-hoc test for GAS and normalization of GAS and BW analyses. Units are arbitrary. ${ }^{* * *} \mathrm{P}<0.001$ vs Time and Group in (B) ${ }^{* * *} \mathrm{P}<$ 0.001 vs CON and ${ }^{\# \#} \mathrm{P}<0.001$ vs $0.1 \mathrm{mg}$ in $(C)$. skeletal muscles. Based on the study results, we conclude that high doses of cisplatin $(0.5 \mathrm{mg} / \mathrm{kg} \mathrm{BW})$ decreased mitochondrial function and downregulated the levels of key modular autophagy-related LC3 II proteins (compared to CON and 0.1 $\mathrm{mg} / \mathrm{kg}$ BW cisplatin).

\section{RESULTS}

\section{Effect of cisplatin reduces BW and gastrocnemius muscle tissue weight}

The BW varied significantly between the groups $(F(1.64,14.73)$ $=63.58, \mathrm{P}<0.001)$ and based on time $(\mathrm{F}(1.86,16.74)=38.09$, $\mathrm{P}<0.001)$. The variation in BW with time was significantly different among the groups $(F(1.46,9.46)=183.7, P<0.001)$. From the baseline up to 14 days, the BW changes differed for the three groups; after 14 days of cisplatin administration, the group administered $0.5 \mathrm{mg} / \mathrm{kg}$ BW showed a significant reduction in BW (Fig. 1A). The tissue weight (g) of the gastrocnemius (GAS) skeletal muscle was also significantly different among the three groups $(F=43.98, P<0.001)$. The BW of the $0.5 \mathrm{mg}$ group $(\mathrm{n}=9,2.20 \pm 0.13)$ was significantly lower than that of the CON $(\mathrm{n}=8,3.42 \pm 0.08, \mathrm{~F}=11.91, \mathrm{P}<$ $0.001)$ and $0.1 \mathrm{mg}$ groups $(\mathrm{n}=5,3.40 \pm 0.07, \mathrm{~F}=10.21, \mathrm{P}<$ 0.001) (Fig. 1C). Moreover, the normalization of GAS muscle tissue based on BW did not reveal a significant difference $(\mathrm{F}=$ $0.17, \mathrm{P}=0.84)$ between the CON $(\mathrm{n}=6,1.04 \pm 0.02), 0.1 \mathrm{mg}$ $(\mathrm{n}=4,1.04 \pm 0.02)$, and $0.5 \mathrm{mg}(\mathrm{n}=6,1.03 \pm 0.01)$ groups (Fig. 1D).

\section{Effect of cisplatin on mitochondrial function in skeletal muscle}

As shown in Fig. 2, the levels of all mitochondrial functions namely glutamate $(\mathrm{GM})$ (Fig. $2 \mathrm{~A}, \mathrm{~F}=3.80, \mathrm{P}<0.05$ ), adenosine di-phosphate (ADP) (Fig. 2B, $F=18.99, \mathrm{P}<0.001$ ), and succinate (SUCC) (Fig. 2C, F $=9.93, \mathrm{P}<0.01$ ), and the respiratory control ratio RCR (Fig. $2 \mathrm{D}, \mathrm{F}=7.08, \mathrm{P}<0.01$ ) significantly differed among the CON, $0.1 \mathrm{mg}$, and $0.5 \mathrm{mg}$ groups. The mitochondria in the GAS skeletal muscle showed

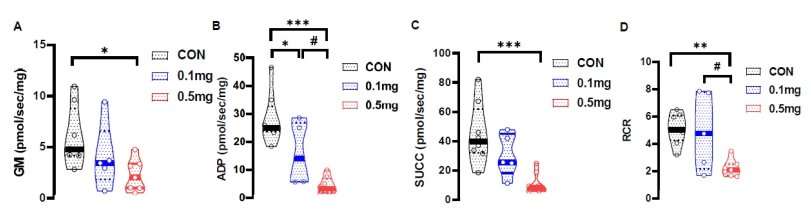

Fig. 2. Effect of cisplatin on mitochondrial function in skeletal muscle. (A) GM levels. (B) ADP levels. (C) SUCC levels. (D) RCR levels. Values were determined by densitometric quantification and are shown as the mean \pm standard error of the mean (SEM). Outliers in each group were excluded. $\mathrm{CON}$, saline control; 0.1 $\mathrm{mg}, 0.1 \mathrm{mg} / \mathrm{kg}$ BW of cisplatin; and $0.5 \mathrm{mg}, 0.5 \mathrm{mg} / \mathrm{kg}$ BW of cisplatin, administered in skeletal muscle. Statistical analysis was performed using one-way ANOVA with Tukey's post-hoc test. BW, body weight. Units are arbitrary. ${ }^{*} \mathrm{P}<0.05,{ }^{*} \mathrm{P}<0.01$, $* * * P<0.001$ vs CON and ${ }^{\#} P<0.05$ vs $0.1 \mathrm{mg}$. 
significantly reduced ADP levels (Fig. $2 \mathrm{~B}$ ) in the $0.5 \mathrm{mg}$ group $(\mathrm{n}=8,4.42 \pm 1.05)$ compared to those in the CON $(\mathrm{n}=8$, $28.01 \pm 3.11, \mathrm{P}<0.001)$ and $0.1 \mathrm{mg}$ groups $(\mathrm{n}=5,15.84$ $\pm 4.76, \mathrm{P}<0.05)$. As shown in Fig. $2 \mathrm{~A}$, the GM levels were significantly decreased only in the $0.5 \mathrm{mg}$ group $(\mathrm{n}=7,2.27 \pm$ $0.59, \mathrm{P}<0.05)$ than in the CON $(\mathrm{n}=8,5.95 \pm 1.01)$ group. The SUCC levels (Fig. 2C) were also lower in the $0.5 \mathrm{mg}$ group $(\mathrm{n}=8,11.06 \pm 2.45, \mathrm{P}<0.001)$ than in the CON group $(\mathrm{n}=$ $8,44.82 \pm 7.27$ ). The RCR level (Fig. 2D) in the $0.5 \mathrm{mg}$ group $(\mathrm{n}=7,2.23 \pm 0.24)$ was the lowest among the three groups $(\mathrm{CON}(\mathrm{n}=8,5.10 \pm 0.39, \mathrm{P}<0.01)$ and $0.1 \mathrm{mg}(\mathrm{n}=5$, $4.94 \pm 1.27, \mathrm{P}<0.05)$ groups).

\section{Effect of cisplatin on autophagy-related proteins in skeletal muscle}

Injection of cisplatin ( $<0.1 \mathrm{mg} / \mathrm{kg} \mathrm{BW})$ in the GAS muscle did not cause changes in the levels of autophagy-related proteins, while $0.5 \mathrm{mg} / \mathrm{kg}$ BW cisplatin injection significantly activated the conversion of LC3II to LC3I (Fig. 3E, F $(2,21)=37.63, \mathrm{P}<$ 0.001 ), increasing the $L C 3 I / L C 3 I$ ratio (Fig. $3 B, F(2,21)=$ 14.01, $\mathrm{P}<0.001)$. The expression of Beclin 1 (Fig. 3C, F (2, $18)=25.98, \mathrm{P}<0.001$ ) and BNIP3 (Fig. 3D, F (2.20) = 42.13, $\mathrm{P}<0.001)$ increased significantly in the $0.5 \mathrm{mg}$ group, but there was no change in Beclin 1 expression in the $0.1 \mathrm{mg}$ group. The p62 content did not change with cisplatin administration (Fig. 3F, F $(2,21)=0.73, \mathrm{P}=0.49)$.

\section{Correlation between RCR and autophagy-related proteins in} skeletal muscle

As seen in Fig. 4, significant correlations were observed be-
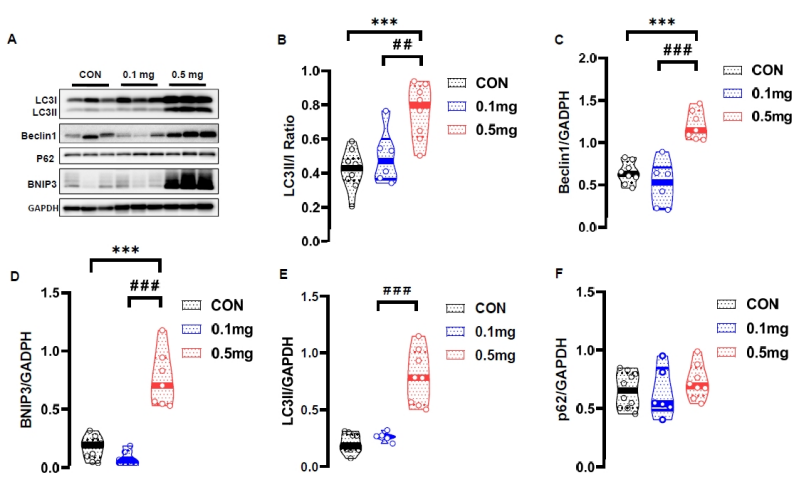

Fig. 3. Effect of cisplatin on autophagy-related proteins in skeletal muscle. (A) Representative images of western blots. (B) LC3II/I ratio. (C) Beclin1/GADPH. (D) BNIP3/GADPH. (E) LC3II/GADPH (F) p62/ GADPDH. Values were determined by densitometric quantification and are shown as the mean \pm standard error of the mean (SEM). BW, body weight; GAS, gastrocnemius; $\mathrm{CON}$, saline control $(\mathrm{n}=$ 10), $0.1 \mathrm{mg}, 0.1 \mathrm{mg} / \mathrm{kg}$ BW of cisplatin ( $\mathrm{n}=6$ ), and $0.5 \mathrm{mg}$, $0.5 \mathrm{mg} / \mathrm{kg}$ BW of cisplatin ( $\mathrm{n}=8)$, administered in skeletal muscle. Statistical analysis was performed using one-way ANOVA with Tukey's post-hoc test. Units are arbitrary. ${ }^{* * * P}<0.001$ vs $\mathrm{CON}$ and ${ }^{\# \#} \mathrm{P}<0.01$, \#\#\# $\mathrm{P}<0.001$ vs $0.1 \mathrm{mg}$. tween RCR (ADP/GM) and LC3 II/GAPDH (Fig. 4A, $r=-0.61$, $95 \% \mathrm{Cl}=-0.83,-0.22, \mathrm{P}<0.01$ ), the $\mathrm{LC} 3 \mathrm{II} / \mathrm{I}$ ratio (Fig. 4B $r$ $=-0.57,95 \% \mathrm{Cl}=-0.81-0.15, \mathrm{P}<0.05)$, Beclin 1/GAPDH (Fig. 4D, $r=-0.83,95 \% \mathrm{Cl}=-0.94-0.59, \mathrm{P}<0.001$ ), and BNIP3/GAPDH (Fig. 4E, $r=-0.55,95 \% \mathrm{Cl}=-0.80-0.12, \mathrm{P}$ $<0.05)$. However, the correlation between RCR and p62 was not significant (Fig. 4C, $r=-.21,95 \% \mathrm{Cl}=-60-0.26, \mathrm{P}>$ 0.05). The strong correlation of Beclin1 and LC3II with RCR indicated that high levels of RCR resulted in lower levels of autophagy-related proteins.

\section{DISCUSSION}

In this study, differences in skeletal muscle tissue weight, BW, mitochondrial function, and autophagy-related protein levels in GAS skeletal muscles among the CON, $0.1 \mathrm{mg}$, and $0.5 \mathrm{mg}$ groups were analyzed. The results showed that the skeletal muscle tissue weight, BW, and mitochondrial function (GM, $A D P, S U C C$, and RCR) were reduced in the $0.5 \mathrm{mg}$ cisplatin group. In addition, the levels of autophagy-related proteins (Beclin 1, BNIP3, and LC3II) in skeletal muscles were increased in the $0.5 \mathrm{mg}$ group. These results indicate that the administration of $0.5 \mathrm{mg} / \mathrm{kg}$ BW of cisplatin decreased the muscle weight, BW, and mitochondrial function and increased the levels of autophagy-related proteins.

Cisplatin administration is associated with severe skeletal muscle dysfunction (6). Among the various forms of cisplatin-induced muscle dysfunction, the most relevant is muscle mass loss (7). This study found that the reduction in BW and muscle tissue weight was higher in the $0.5 \mathrm{mg}$ group than in the CON and $0.1 \mathrm{mg}$ groups (Fig. 1B, C). In addition, the normalization of skeletal muscle tissue based on BW did not reveal any significant differences among the three groups, indicating that

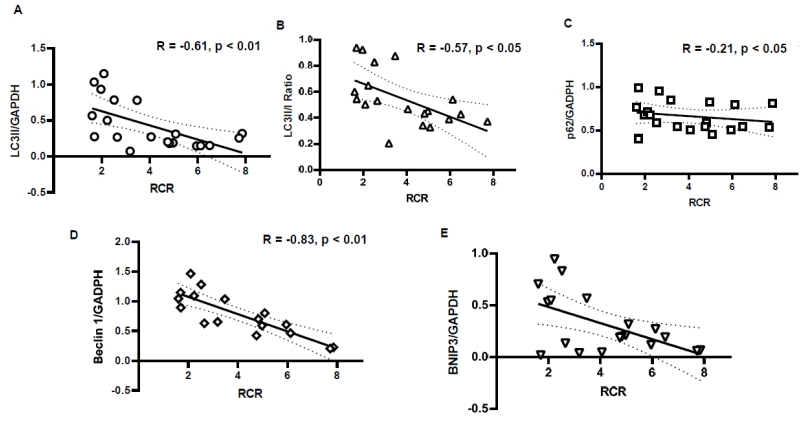

Fig. 4. Correlation between mitochondrial function RCR and the expression of autophagy-related proteins in the GAS skeletal muscle. Correlation of RCR with (A) LC3II/GAPDH, (B) LC3II/I ratio, (C) p62/GAPDH, (D) Beclin 1/GADPH, and (E) BNIP3/GADPH. Values were determined by densitometric quantification and are shown as the mean \pm standard error of the mean (SEM). Extreme outliers were excluded. Statistical analysis was performed using Pearson's correlation coefficient (R). 
the administration of higher cisplatin doses (up to $0.5 \mathrm{mg}$ ) results in muscle atrophy (Fig. 1D). These findings may indicate a specific molecular mechanism, i.e., cisplatin-induced muscle atrophy may be specifically related to the transcript-level expression of muscle atrophy F-box (MAFbx), muscle RING fiber-1 (MuRF1), and Atrogin-1 $(4,8)$. Muscle mass is also regulated through the IGF-1/PI3K/AKT/mTOR pathway, preventing muscle atrophy (28). However, in this study, we did not analyze the specific muscle atrophy levels associated with cisplatin administration, and further studies are needed to elucidate the influence of these factors at different cisplatin concentrations.

Mitochondria are dynamic organelles whose function and morphology is altered through fission and fusion (29). Mitochondrial dysfunction following cisplatin administration resulted in damaged mtDNA, which decreased mitochondrial biogenesis and activity (30). Our results revealed a decrease in GM, ADP, SUCC, and RCR levels in the $0.5 \mathrm{mg}$ group (Fig. 2). In addition, the RCR, an indicator of oxidative phosphorylation, dramatically decreased in the $0.5 \mathrm{mg}$ group. It may be inferred that treatment of wild type cells with cisplatin resulted in decreased RCR (17). These results indicated that at high concentrations, cisplatin induced a lower capacity for oxidation and ATP turnover and increased the proton peak in mitochondria $(6,17,31)$. Moreover, our findings showed that cisplatininduced toxicity can result in metabolic dysfunction (32) and production of mitochondrial reactive oxygen species (ROS). The lowest SUCC levels in the $0.5 \mathrm{mg}$ group in this study were related to skeletal muscle apoptosis (33). Considering our results as a whole, it can be inferred that high doses of cisplatin can cause mitochondrial dysfunction, including decreased RCR levels, leading to ROS production and skeletal muscle cell apoptosis.

The highest levels of autophagy-related proteins, such as LC3 II, Beclin 1, and BNIP3, and LC3 II/I ratio were observed in the $0.5 \mathrm{mg}$ group (Fig. 3). Autophagy is a major metabolic regulator of resistance to chemotherapy (22). Inhibition of autophagy increases cisplatin-induced apoptotic cell death (34). Our findings are similar to those of previous studies that observed mitochondrial dysfunction (Fig. 2) and upregulation of Beclin 1 and LC3 II (Fig. 3C, E) in cisplatin-induced cachexia of the skeletal muscle (20). In addition, a previous study indicated that $\mathrm{C} 2 \mathrm{C} 12$ muscle cells treated with $50 \mu \mathrm{M}$ cisplatin for $24 \mathrm{~h}$ exhibited upregulated expression of Beclin 1, BNIP3, and muscle atrophy-related atrogin-1 (35). These results are consistent with our findings, which showed that cisplatin $(0.5 \mathrm{mg})$ increased muscle atrophy and the expression of autophagyrelated proteins (Fig. 1) in the skeletal muscle. effect of cisplatin administration and muscle atrophy and mitochondrial dysfunction is mediated through AKT phosphorylation that results in dephosphorylation of FOXO3a, which then migrates to the nucleus to activate the transcription of autophagy-specific genes (e.g., LC3 II and Beclin1) and causes muscle atrophy (Murf 1 and BNIP3) (6, 36, 37). Overall, our findings support the results of previous studies that show that administration of high doses of cisplatin can cause an increase in the levels of autophagy-related proteins (LC3 II, Beclin 1, and BNIP3) as well as muscle atrophy. However, our study did not consider a cancer cachexia animal model, and further studies are required to analyze mitochondrial function, skeletal muscle morphology, and autophagy response in such a model.

Mitochondrial function, especially RCR(ADP/GM), is associated with autophagy-related proteins (Fig. 4). Mitochondrial function is affected by autophagy in various metabolic diseases (38). An acute kidney injury model administered with cisplatin showed that an increased level of LC3 II was associated with mitochondrial dysfunction in the context of increased ROS levels and decreased levels of Drp1, Opa1, ATP5a, Sirt3, and Ndufs4 (39). Our findings supported these results, which showed an increase in the RCR, indicating that mitochondrial function influenced the reduced levels of autophagy-related proteins, including LC3 II, Beclin 1, and BNIP3, and the LC3 II/I ratio in cisplatin-administered skeletal muscle. The results suggest that activation of extracellular signal-regulated kinase by cisplatin decreased the LC3 II levels (40). However, we did not quantify the mitochondrial protein levels; therefore, further studies are required to analyze mitochondrial protein levels and function by comparing autophagy-related functions.

This study revealed that administration of cisplatin in rat models affected the skeletal muscle weight, BW, mitochondrial function, and autophagy-related protein levels in skeletal muscles. The highest dose of cisplatin (i.e., $0.5 \mathrm{mg} / \mathrm{kg} \mathrm{BW}$ ) induced remarkedly deleterious effects, with a decreased muscle mass and mitochondrial dysfunction and increased levels of autophagy-related proteins. These results suggest that cisplatin administration for cancer treatment may be safer and more beneficial when used in combination with additional agents that reduce mitochondrial dysfunction and autophagy pathway activity to prevent skeletal muscle dysfunction, thereby providing further insights to develop novel therapeutic approaches.

\section{MATERIALS AND METHODS}

Materials and methods are available in the Supplemental Materials.

\section{ACKNOWLEDGEMENTS}

This work was supported by the Ministry of Education of the Republic of Korea and the National Research Foundation of Korea (NRF-2018S1A5A8027802). We thank Dr. Jeong Rim Ko for performing cisplatin-administered animal models.

\section{CONFLICTS OF INTEREST}

The authors have no conflicting interests.

\section{REFERENCES}

1. Frezza M, Hindo S, Chen D et al (2010) Novel metals and 
metal complexes as platforms for cancer therapy. Curr Pharm Des 16, 1813-1825

2. Kelland $L$ (2007) The resurgence of platinum-based cancer chemotherapy. Nat Rev Cancer 7, 573-584

3. Jung ET, Koh DS, Lim YH, Shin SY and Lee YH (2020) Overcoming multidrug resistance by activating unfolded protein response of the endoplasmic reticulum in cisplatinresistant A2780/CisR ovarian cancer cells. BMB Rep 53, 88-93

4. Sakai H, Sagara A, Arakawa K et al (2014) Mechanisms of cisplatin-induced muscle atrophy. Toxicol Appl Pharmacol 278, 190-199

5. Jin YJ, Huynh DTN, Kang KW, Myung CS and Heo KS (2019) Inhibition of p90RSK activation sensitizes triplenegative breast cancer cells to cisplatin by inhibiting proliferation, migration and EMT. BMB Rep 52, 706-711

6. Conte E, Bresciani E, Rizzi L et al (2020) Cisplatin-induced skeletal muscle dysfunction: mechanisms and counteracting therapeutic strategies. Int J Mol Sci 21, 1242

7. Fearon K, Strasser F, Anker SD et al (2011) Definition and classification of cancer cachexia: an international consensus. Lancet Oncol 12, 489-495

8. Conte E, Camerino GM, Mele A et al (2017) Growth hormone secretagogues prevent dysregulation of skeletal muscle calcium homeostasis in a rat model of cisplatininduced cachexia. J Cachexia Sarcopenia Muscle 8, 386404

9. Bresciani E, Rizzi L, Molteni L et al (2017) JMV2894, a novel growth hormone secretagogue, accelerates body mass recovery in an experimental model of cachexia. Endocrine 58, 106-114

10. Sakai H, Sagara A, Arakawa K et al (2014) Mechanisms of cisplatin-induced muscle atrophy. Toxicol Appl Pharmacol 278, 190-199

11. Dickey DT, Muldoon LL, Doolittle ND, Peterson DR, Kraemer DF and Neuwelt EA (2008) Effect of N-acetylcysteine route of administration on chemoprotection against cisplatin-induced toxicity in rat models. Cancer Chemother Pharmacol 62, 235-241

12. Garcia JM, Cata JP, Dougherty PM and Smith RG (2008) Ghrelin prevents cisplatin-induced mechanical hyperalgesia and cachexia. Endocrinology 149, 455-460

13. Park SE, Choi JH, Park JY et al (2020) Loss of skeletal muscle mass during palliative chemotherapy is a poor prognostic factor in patients with advanced gastric cancer. Sci Rep 10, 17683

14. Lin JF, Lin YC, Tsai TF, Chen HE, Chou KY and Hwang TIS (2017) Cisplatin induces protective autophagy through activation of BECN1 in human bladder cancer cells. Drug Des Devel Ther 11, 1517-1533

15. Cocetta V, Ragazzi E and Montopoli M (2019) Mitochondrial involvement in cisplatin resistance. Int J Mol Sci 20, 3384

16. Lomeli N, Di K, Czerniawski J, Guzowski JF and Bota DA (2017) Cisplatin-induced mitochondrial dysfunction is associated with impaired cognitive function in rats. Free Radic Biol Med 102, 274-286

17. Inapurapu SP, Kudle KR, Bodiga S and Bodiga VL (2017) Cisplatin cytotoxicity is dependent on mitochondrial respiration in Saccharomyces cerevisiae. Iran J Basic Med
Sci 20, 83-89

18. Sartori R, Romanello V, Sandri M (2021) Mechanisms of muscle atrophy and hypertrophy: implications in health and disease. Nat Commun 12, 330

19. Romanello $V$ and Sandri M (2015) Mitochondrial quality control and muscle mass maintenance. Front Physiol 6, 422

20. Sirago G, Conte E, Fracasso F et al (2017) Growth hormone secretagogues hexarelin and JMV2894 protect skeletal muscle from mitochondrial damages in a rat model of cisplatin-induced cachexia. Sci Rep 7, 1-14

21. Hood DA, Memme JM, Oliveira AN and Triolo M (2019) Maintenance of skeletal muscle mitochondria in health, exercise, and aging. Annu Rev Physiol 81, 19-41

22. Poillet Perez L, Sarry JE and Joffre C (2021) Autophagy is a major metabolic regulator involved in cancer therapy resistance. Cell Rep 36, 109528

23. Paolini A, Omairi S, Mitchell R et al (2018) Attenuation of autophagy impacts on muscle fibre development, starvation induced stress and fibre regeneration following acute injury. Sci Rep 8, 9062

24. Gąsiorkiewicz BM, Koczurkiewicz-Adamczyk P, Piska K and Pękala E (2021) Autophagy modulating agents as chemosensitizers for cisplatin therapy in cancer. Invest New Drugs 39, 538-563

25. Dikic I and Elazar Z (2018) Mechanism and medical implications of mammalian autophagy. Nat Rev Mol Cell Biol 19, 349-364

26. Yu L, Chen $Y$ and Tooze SA (2018) Autophagy pathway: Cellular and molecular mechanisms. Autophagy 14, 207215

27. Metaxakis A, Ploumi C and Tavernarakis N (2018) Autophagy in age-associated neurodegeneration. Cells 7, 37

28. Banerjee A and Guttridge DC (2012) Mechanisms for maintaining muscle. Curr Opin Support Palliat Care 6, 451-456

29. Youle RJ and Van Der Bliek AM (2012) Mitochondrial fission, fusion, and stress. Science 337, 1062-1065

30. Kleih M, Böpple K, Dong M et al (2019) Direct impact of cisplatin on mitochondria induces ROS production that dictates cell fate of ovarian cancer cells. Cell Death Dis 10, 851

31. Gordon JA and Gattone N (1986) Mitochondrial alterations in cisplatin-induced acute renal failure. Am J Physiol 250, F991-F998

32. Choi YM, Kim HK, Shim W et al (2015) Mechanism of cisplatin-induced cytotoxicity is correlated to impaired metabolism due to mitochondrial ROS generation. PLoS One 10, e0135083

33. Kruspig B, Valter K, Skender B, Zhivotovsky B and Gogvadze $V$ (2016) Targeting succinate: ubiquinone reductase potentiates the efficacy of anticancer therapy. Biochim Biophys Acta 1863, 2065-2071

34. Chen J, Zhang L, Zhou H et al (2018) Inhibition of autophagy promotes cisplatin-induced apoptotic cell death through Atg5 and Beclin 1 in A549 human lung cancer cells. Mol Med Rep 17, 6859-6865

35. Fanzani A, Zanola A, Rovetta F, Rossi S and Aleo MF (2011) Cisplatin triggers atrophy of skeletal C2C12 myotubes via impairment of Akt signalling pathway and sub- 
sequent increment activity of proteasome and autophagy systems. Toxicol Appl Pharmacol 250, 312-321

36. Sandri M (2010) Autophagy in skeletal muscle. FEBS Lett $584,1411-1416$

37. Sandri M, Sandri C, Gilbert A et al (2004) Foxo transcription factors induce the atrophy-related ubiquitin ligase atrogin-1 and cause skeletal muscle atrophy. Cell 117, 399-412

38. Rambold AS and Lippincott-Schwartz J (2011) Mechanisms of mitochondria and autophagy crosstalk. Cell Cycle 10, 4032-4038

39. Zhu L, Yuan Y, Yuan L et al (2020) Activation of TFEBmediated autophagy by trehalose attenuates mitochondrial dysfunction in cisplatin-induced acute kidney injury. Theranostics 10, 5829-5844

40. Wang J and Wu GS (2014) Role of autophagy in cisplatin resistance in ovarian cancer cells. J Biol Chem 289, 1716317173 